\title{
Effects of hydrogen sulfide on inducible nitric oxide synthase activity and expression of cardiomyocytes in diabetic rats
}

\author{
RUI YANG $^{1 *}$, QIANG JIA $^{1 *}$, XIAO-FEN LIU ${ }^{1}$, YUAN-YUAN WANG $^{2}$ and SHAN-FENG MA ${ }^{1}$ \\ ${ }^{1}$ Department of Physiology; ${ }^{2}$ Center of Functional Experiment, \\ Bengbu Medical College, Bengbu, Anhui 233030, P.R. China
}

Received March 5, 2017; Accepted August 8, 2017

DOI: $10.3892 / \mathrm{mmr} .2017 .7247$

\begin{abstract}
The aim of the present study was to investigate the effects of hydrogen sulfide $\left(\mathrm{H}_{2} \mathrm{~S}\right)$ on the activity and expression of inducible nitric oxide synthase (iNOS) in the myocardial tissue of type 1 diabetic rats. Rats were divided randomly into four groups: Normal control (NC), diabetes mellitus (DM), DM+DL-Proparglygylcine (DM+PAG) and DM+sodium hydrosulfide (DM+NaHS) groups. Type 1 diabetes was induced in the respective groups by a single intraperitoneal (i.p.) injection of streptozotocin. Rats in the $\mathrm{DM}+\mathrm{PAG}$ and DM+NaHS groups were injected with PAG and NaHS (i.p.) once a day, respectively. The level of fasting blood glucose (FBG), the heart-weight to body-weight (HW/BW) ratio and the ventricular hemodynamic parameters were measured. The activities of serum total NOS (tNOS), iNOS, lactate dehydrogenase ( $\mathrm{LDH})$, creatine kinase $(\mathrm{CK})$ and creatine kinase $\mathrm{MB}$ isozyme (CK-MB), and the content of nitric oxide (NO) were detected. The contents of myocardial malondialdehyde (MDA) and NO, and the activities of superoxide dismutase (SOD), tNOS and iNOS were determined. The myocardial tissue was examined for histological and ultrastructural alterations. The expression level of iNOS at the transcriptional and translational levels in the myocardial tissue was estimated. The level of FBG was increased in the DM group compared with the NC group, verifying the diabetic condition of the rats. The function of the left ventricle, the myocardial histological alterations and ultrastructures were damaged in the DM group. The DM group additionally demonstrated an increase in the serum NO content and tNOS, iNOS, LDH, CK and CK-MB activities. The myocardial MDA, NO content and tNOS levels were additionally increased in this group. The iNOS activity was increased significantly whereas the
\end{abstract}

Correspondence to: Dr Shan-Feng Ma, Department of Physiology, Bengbu Medical College, 2600 Dong Hai Avenue, Bengbu, Anhui 233030, P.R. China

E-mail: msfbio@163.com

${ }^{*}$ Contributed equally

Key words: diabetes mellitus, hydrogen sulfide, rat, myocardium, nitric oxide, inducible nitric oxide synthase myocardial SOD activity was decreased. The increase in the iNOS activity was supported by an enhanced expression level of myocardial iNOS mRNA and protein in the DM group. In the DM+PAG group, in the absence of $\mathrm{H}_{2} \mathrm{~S}$, the dysfunction of the left ventricle and the oxidative stress injury were increased compared with the DM group. The activity and the expression of tNOS and iNOS were increased significantly. However, the rats in the DM+PAG group demonstrated the opposite effects. In conclusion, $\mathrm{H}_{2} \mathrm{~S}$ exhibits a protective effect on the myocardium in type 1 diabetic rats, which may be associated with the suppression of iNOS activity and expression, a decrease in the NO content and the inhibition of oxidative stress injury.

\section{Introduction}

Diabetes mellitus (DM) is a metabolic disease that causes hyperglycemia and a number of serious complications, including cardiovascular disease. Diabetes coupled with cardiovascular disease is a leading cause of morbidity and mortality $(1,2)$. Diabetic cardiomyopathy (DCM) is characterized by a decreased diastolic and systolic myocardial function, independent of coronary artery disease and hypertension, with a risk of heart failure (3). Previous studies have shown that hyperglycemia, lipid accumulation, oxidative stress, calcium overload, mitochondrial dysfunction, myocardial inflammation and apoptosis may be involved in the pathogenesis of DCM $(4,5)$.

Nitric oxide (NO), carbon monoxide (CO) and hydrogen sulfide $\left(\mathrm{H}_{2} \mathrm{~S}\right)$ are members of the modern family of gasotransmitters, which play important regulatory roles in the body (6). NO, the first identified gaseous signaling molecule that can be produced from L-arginine, is catalyzed by the NO synthase (NOS). There are various isoforms of NOS (i.e., nNOS, iNOS, eNOS) in different types of mammalian cells. As an endothelium-derived relaxing factor, physiologically low concentrations of NO can cause the opening of sarcoplasmic reticular ryanodine receptor $\mathrm{Ca}^{2+}$ channels to enhance myocardial contractility. However, high concentrations of NO induce the production of low amounts of cGMP, which reduce myocardial contractile function $(7,8)$. NO is thereby considered to be involved in the regulation of cardiac function.

In the past, $\mathrm{H}_{2} \mathrm{~S}$ was considered as a toxic gas with the odour of rotten eggs. Now $\mathrm{H}_{2} \mathrm{~S}$, the third gas signaling molecule 
identified after $\mathrm{NO}$ and $\mathrm{CO}$, can be generated endogenously by pyridoxal-5'-phosphate-dependent enzymes in the mammalian body, and has a variety of biological functions in tissues and organs (9). In recent years, much evidence has demonstrated that $\mathrm{H}_{2} \mathrm{~S}$ plays a critical role in the physiology and pathophysiology of the cardiovascular system $(10,11)$. DL-Proparglygylcine (PAG) is an irreversible inhibitor of the $\mathrm{H}_{2} \mathrm{~S}$ synthesizing enzyme-cystathionine- $\gamma$-lyase (CSE). PAG can block $\mathrm{H}_{2} \mathrm{~S}$ synthesis activity, thereby decreasing the level of endogenous $\mathrm{H}_{2} \mathrm{~S}$ in vivo, while sodium hydrosulfide (NaHS) serves as a donor of exogenous $\mathrm{H}_{2} \mathrm{~S}$. In a previous study (12), we reported that exogenous $\mathrm{H}_{2} \mathrm{~S}$ could alleviate myocardial injury in diabetic rats; however, the mechanism remains unclear. Several studies have reported that $\mathrm{H}_{2} \mathrm{~S}$ can inhibit the activity of NOS, hence reducing the NO content (13). In the present study, we investigated the protective effects of $\mathrm{H}_{2} \mathrm{~S}$ on the myocardial tissue in diabetic rats, and whether it is associated with the inducible NOS (iNOS)/NO system in the myocardium.

\section{Materials and methods}

Animals. Male Sprague-Dawley rats (160-200 g) were purchased from the Animal Center of Bengbu Medical College (Bengbu, Anhui, China). The rats were fed normal diet and had free access to water. All rats were housed in cages at room temperature $\left(22 \pm 1^{\circ} \mathrm{C}\right)$ with a fixed $12 \mathrm{~h} \mathrm{light/dark} \mathrm{cycle.}$ All animal procedures were conducted in accordance with the United States National Institutes of Health Guide and were approved by the Animal Use and Care Committee of Bengbu Medical College.

Materials and reagents. Streptozotocin, PAG and NaHS were purchased from Sigma-Aldrich (St. Louis, MO, USA). Malondialdehyde (MDA), superoxide dismutase (SOD), lactate dehydrogenase (LDH), creatine kinase (CK), creatine kinase MB isozyme (CK-MB), NO and NOS typed assay kits were purchased from Nanjing Jiancheng Bioengineering Institute (Nanjing, Jiangsu, China). TRIzol (total RNA extraction reagent) was purchased from Invitrogen (Carlsbad, CA, USA). iNOS and $\beta$-actin primers were synthesized by Shanghai Sangon Biological Engineering Co., Ltd., (Shanghai, China). The primers for iNOS were 5'-ATCCCGAAACGCTACACT T-3' and 5'-TCTGGCGAAGAACAATCC-3', the amplified fragment length was $314 \mathrm{bp}$; the primers for $\beta$-actin were 5'-GATGGTGGGTATGGGTCAGAAGGAGG-3' and 5'-GCT CATTGCCGATAGTGATGACC-3', the amplified fragment length was $632 \mathrm{bp}$. Rabbit iNOS antibody was purchased from Abcam (Cambridge, MA, USA). Rabbit $\beta$-actin antibody was purchased from Proteintech Group, Inc. (Wuhan, Hubei, China). Goat anti-rabbit secondary antibody was purchased from Biosharp Company (Hefei, China).

\section{Experimental methods}

Induction of diabetes and experimental protocol. Animals were divided randomly into four groups: Normal control (NC) group, diabetes mellitus (DM) group, DM+DL-Proparglygylcine (DM+PAG) group and DM+sodium hydrosulfide (DM+NaHS) group $(n=8)$. Diabetes was induced in overnight fasted rats by administering a single intraperitoneal (i.p.) injection of $55 \mathrm{mg} / \mathrm{kg}$ streptozotocin freshly dissolved in $0.1 \mathrm{~mol} / \mathrm{l}$ sodium citrate buffer ( $\mathrm{pH} 4.5)$. The rats in the NC group were injected with a similar volume of sodium citrate buffer alone. The rats with plasma fasting blood glucose (FBG) level over than $16.7 \mathrm{mmol} / \mathrm{l}$ (72 $\mathrm{h}$ after injection) were considered as diabetic rats. After successful building models, the rats in the DM+PAG and DM+NaHS groups were injected i.p. with PAG (40 mg/kg/day) and NaHS ( $56 \mu \mathrm{mol} / \mathrm{kg} /$ day) for 8 weeks, respectively. The rats in the $\mathrm{NC}$ and DM groups were injected with a similar volume of normal saline.

Detection of FBG level, body-weight (BW), heart-weight $(H W)$ and $H W / B W$. The plasma FBG level and BW were measured at the end of the 8th week. HW was measured after the rat was sacrificed. The HW/BW ratio was calculated.

Hemodynamic measurements. After treatment for 8 weeks, all rats were anesthetized with i.p. $4 \%$ chloral hydrate $(1 \mathrm{ml} / 100 \mathrm{~g})$, then fixed in the supine position. A tracheal cannula was used to connect the rats to a breathing machine (tidal volume $2-3 \mathrm{ml} / 100 \mathrm{~g}$, respiratory rate $70-80$ times $/ \mathrm{min}$ ). Meanwhile, the right carotid artery was intubated to the left ventricle, connecting and opening the Med-Lab Biological Recording system (Nanjing MedEase Technology Co., Ltd., Nanjing, China). Left ventricular systolic pressure (LVSP), left ventricular end-diastolic pressure (LVEDP) and maximal rise/fall rate of left ventricular pressure $\left( \pm d p / d t_{\max }\right)$ were recorded.

Serum NO contentand tNOS, iNOS, $L D H, C K, C K-M B$ activities measurement. At the end of hemodynamic measurements, arterial blood was collected and placed in centrifuge tubes and centrifuged at 3,000 rpm/min for $20 \mathrm{~min}$. The supernatant fluid was collected. NO content and total NOS (tNOS), iNOS, LDH, CK, CK-MB activities were measured by commercially available kits according to the manufacturer's instructions.

Myocardial NO, MDA contents and tNOS, iNOS, SOD activities measurement. At the end of the experimental period, $0.1 \mathrm{~g}$ myocardial tissue was homogenized in $0.9 \mathrm{ml}$ ice-cold normal saline. The supernatant was collected after centrifugation for $20 \mathrm{~min}(3,000 \mathrm{rpm} / \mathrm{min})$. The protein concentration was measured by the bicinchoninic acid (BCA) Protein Assay kit. NO, MDA contents and tNOS, iNOS, SOD activities were estimated in the myocardial tissue according to the instruction manual, separately.

Histological observation by hematoxylin and eosin $(H \& E)$ staining. For histological analysis by light microscope, the myocardial tissue was harvested and fixed in $4 \%$ paraformaldehyde for $24 \mathrm{~h}$, embedded in paraffin and cut into $5 \mu \mathrm{m}$ thick serial sections, and then stained with H\&E for light microscope observation.

Ultrastructure observation under transmission electron microscope. Hearts were dissected and small pieces were fixed with $2.5 \%$ glutaraldehyde in $0.1 \mathrm{~mol} / 1$ cacodylate buffer for $2 \mathrm{~h}$, post-fixed in $1 \%$ osmium tetroxide in $0.1 \mathrm{~mol} / 1$ cacodylate buffer for $1 \mathrm{~h}$. Ultrathin sections were cut and contrasted with uranyl acetate followed by lead citrate and 
Table I. Levels of FBG, BW, HW and HW/BW in the different groups.

\begin{tabular}{lccrc}
\hline Group & FBG $(\mathrm{mmol} / \mathrm{l})$ & BW $(\mathrm{g})$ & $\mathrm{HW}(\mathrm{mg})$ & $\mathrm{HW} / \mathrm{BW}(\mathrm{mg} / \mathrm{g})$ \\
\hline NC & $5.67 \pm 0.91$ & $437.19 \pm 27.13$ & $1,266.87 \pm 110.22$ & $2.96 \pm 0.25$ \\
DM & $25.17 \pm 3.79^{\mathrm{a}}$ & $217.50 \pm 20.81^{\mathrm{a}}$ & $810.68 \pm 50.98^{\mathrm{a}}$ & $3.78 \pm 0.31^{\mathrm{a}}$ \\
DM+PAG & $26.23 \pm 3.82$ & $189.73 \pm 18.42^{\mathrm{b}}$ & $779.21 \pm 42.43$ & $4.15 \pm 0.35^{\mathrm{b}}$ \\
DM+NaHS & $22.04 \pm 3.66$ & $270.16 \pm 24.73^{\mathrm{c}}$ & $1,017.45 \pm 82.39^{\mathrm{c}}$ & $3.34 \pm 0.32^{\mathrm{c}}$ \\
\hline
\end{tabular}

Data were expressed as the mean \pm standard deviation $(\mathrm{n}=8)$. ${ }^{\mathrm{P}} \mathrm{P}<0.01 \mathrm{vs}$. $\mathrm{NC}$ group; ${ }^{\mathrm{b}} \mathrm{P}<0.05,{ }^{\mathrm{c}} \mathrm{P}<0.01$ vs. DM group; $\mathrm{NC}$, normal control group; $\mathrm{DM}$, diabetes mellitus group; DM+PAG, DM treatment with PAG group; DM+NaHS, DM treatment with NaHS group; FBG, fasting blood glucose; BW, body-weight; HW, heart-weight; HW/BW, heart-weight to body-weight ratio.

Table II. Alterations of ventricular hemodynamic parameters in the different groups.

\begin{tabular}{lcccc}
\hline Group & LVSP $(\mathrm{kPa})$ & $\operatorname{LVEDP}(\mathrm{kPa})$ & $+d p / d t_{\max }(\mathrm{kPa} / \mathrm{s})$ & $-d p / d t_{\max }(\mathrm{kPa} / \mathrm{s})$ \\
\hline $\mathrm{NC}$ & $10.95 \pm 1.08$ & $0.22 \pm 0.04$ & $645.29 \pm 57.45$ & $456.43 \pm 47.37$ \\
DM & $7.67 \pm 0.67^{\mathrm{a}}$ & $0.43 \pm 0.07^{\mathrm{a}}$ & $310.90 \pm 43.80^{\mathrm{a}}$ & $249.10 \pm 28.75^{\mathrm{a}}$ \\
DM+PAG & $6.54 \pm 0.62^{\mathrm{b}}$ & $0.51 \pm 0.06^{\mathrm{c}}$ & $259.34 \pm 40.71^{\mathrm{b}}$ & $207.56 \pm 27.08^{\mathrm{b}}$ \\
DM+NaHS & $8.82 \pm 0.85^{\mathrm{c}}$ & $0.34 \pm 0.05^{\mathrm{c}}$ & $483.45 \pm 52.12^{\mathrm{c}}$ & $393.14 \pm 40.33^{\mathrm{c}}$ \\
\hline
\end{tabular}

Data were expressed as the mean \pm standard deviation $(\mathrm{n}=8)$. ${ }^{\mathrm{a}} \mathrm{P}<0.01 \mathrm{vs}$. $\mathrm{NC}$ group; ${ }^{\mathrm{b}} \mathrm{P}<0.05,{ }^{\mathrm{c}} \mathrm{P}<0.01 \mathrm{vs}$. DM group; $\mathrm{NC}$, normal control group; $\mathrm{DM}$, diabetes mellitus group; DM+PAG, DM treatment with PAG group; DM+NaHS, DM treatment with NaHS group; LVSP, left ventricular systolic pressure; LVEDP, left ventricular end diastolic pressure; $+d p / d t_{\max }$, maximal rise rate of left ventricular pressure; $-d p / d t_{\max }, \operatorname{maximal}$ fall rate of left ventricular pressure.

observed with JEM-1230 transmission electron microscope from Jeol, Ltd. (Tokyo, Japan).

Detection of levels of iNOS $m R N A$ by reverse transcription polymerase chain reaction ( $R T-P C R)$. RT-PCR was used to detect the expression of iNOS mRNA in myocardium. Briefly, total RNA was extracted with TRIzol according to the manufacturer's instructions. Executing sequentially RNA detection, reverse transcription reaction, $\mathrm{PCR}$ amplification $\left(95^{\circ} \mathrm{C}\right.$ predenaturation for $3 \mathrm{~min} ; 95^{\circ} \mathrm{C}$ denaturation for $50 \mathrm{sec} ; \beta$-actin: $59.4^{\circ} \mathrm{C}$, iNOS: $53.9^{\circ} \mathrm{C}$ annealing for $50 \mathrm{sec} ; 72^{\circ} \mathrm{C}$ extension $60 \mathrm{sec} ; 72^{\circ} \mathrm{C}$ balancing for $10 \mathrm{~min}$ after 35 cycles; $4^{\circ} \mathrm{C}$ heat preservation). The PCR products were analyzed on $1.2 \%$ agarose gel. The densitometry results for the iNOS gene were compared with the corresponding $\beta$-actin levels to account for loading differences.

Detection of iNOS protein by western blot analysis. After the experiment, $0.1 \mathrm{~g}$ myocardial tissue was collected from each group and homogenized in $1 \mathrm{ml}$ protein extraction buffer $(10 \mu \mathrm{l}$ Phenylmethanesulfonyl fluoride/PMSF+990 $\mu 1$ lysis buffer). The supernatant was collected after centrifugation and protein concentration was determined using the BCA Protein Assay kit. The quantity of total protein sample is $35 \mu \mathrm{g}$, the protein was diluted by SDS-PAGE loading buffer. Executing sequentially degeneration, adding the sample, electrophoresis, transferred to a polyvinylidene difluoride (PVDF) membrane. The membranes were blocked with $5 \%$ nonfat milk in Tris- buffered saline Tween (TBST) at $37^{\circ} \mathrm{C}$ for $2 \mathrm{~h}$, and then they were incubated at $4^{\circ} \mathrm{C}$ overnight with rabbit iNOS antibody $(1: 1,000)$ and rabbit $\beta$-actin antibody $(1: 2,000)$. All membranes were incubated for $1 \mathrm{~h}$ with HRP-linked anti-rabbit IgG $(1: 2,000)$ secondary antibody. The membranes were developed by the chemiluminescent HRP substrate. Signals were detected with ChemiDoc XRS system (Bio-Rad, Berkeley, CA, USA). Grey values of protein bands were analyzed by Quantity One software.

Statistical analysis. Data were expressed as mean \pm SD. Statistical comparisons were performed by one-way analysis of variance (ANOVA) and the Newman-Keuls test. $\mathrm{P}<0.05$ was considered to indicate a statistically significant difference.

\section{Results}

Changes of $F B G, B W, H W$ and $H W / B W$. Compared with the NC group, FBG and $\mathrm{HW} / \mathrm{BW}$ were significantly increased $(\mathrm{P}<0.01)$, while $\mathrm{BW}$ and $\mathrm{HW}$ were decreased $(\mathrm{P}<0.01)$ in the $\mathrm{DM}$ group. In contrast to $\mathrm{DM}$ group, $\mathrm{BW}$ was decreased $(\mathrm{P}<0.05)$ and $\mathrm{HW} / \mathrm{BW}$ was increased $(\mathrm{P}<0.05)$ in the $\mathrm{DM}+\mathrm{PAG}$ group; $\mathrm{BW}$ and $\mathrm{HW}$ were increased $(\mathrm{P}<0.01), \mathrm{HW} / \mathrm{BW}$ was significantly decreased $(\mathrm{P}<0.01)$ in the $\mathrm{DM}+\mathrm{NaHS}$ group (Table I).

Changes of hemodynamic parameters. Compared with the NC group, LVSP and $\pm d p / d t_{\max }$ were decreased $(\mathrm{P}<0.01)$, while LVEDP was increased $(\mathrm{P}<0.01)$ in the $\mathrm{DM}$ group; In contrast to DM group, LVSP and $\pm d p / d t_{\max }$ were decreased $(\mathrm{P}<0.05)$, while LVEDP was increased $(\mathrm{P}<0.01)$ in the $\mathrm{DM}+\mathrm{PAG}$ group; LVSP and $\pm d p / d t_{\max }$ were increased $(\mathrm{P}<0.01)$, while LVEDP was decreased $(\mathrm{P}<0.01)$ in the $\mathrm{DM}+\mathrm{NaHS}$ group (Table II). 

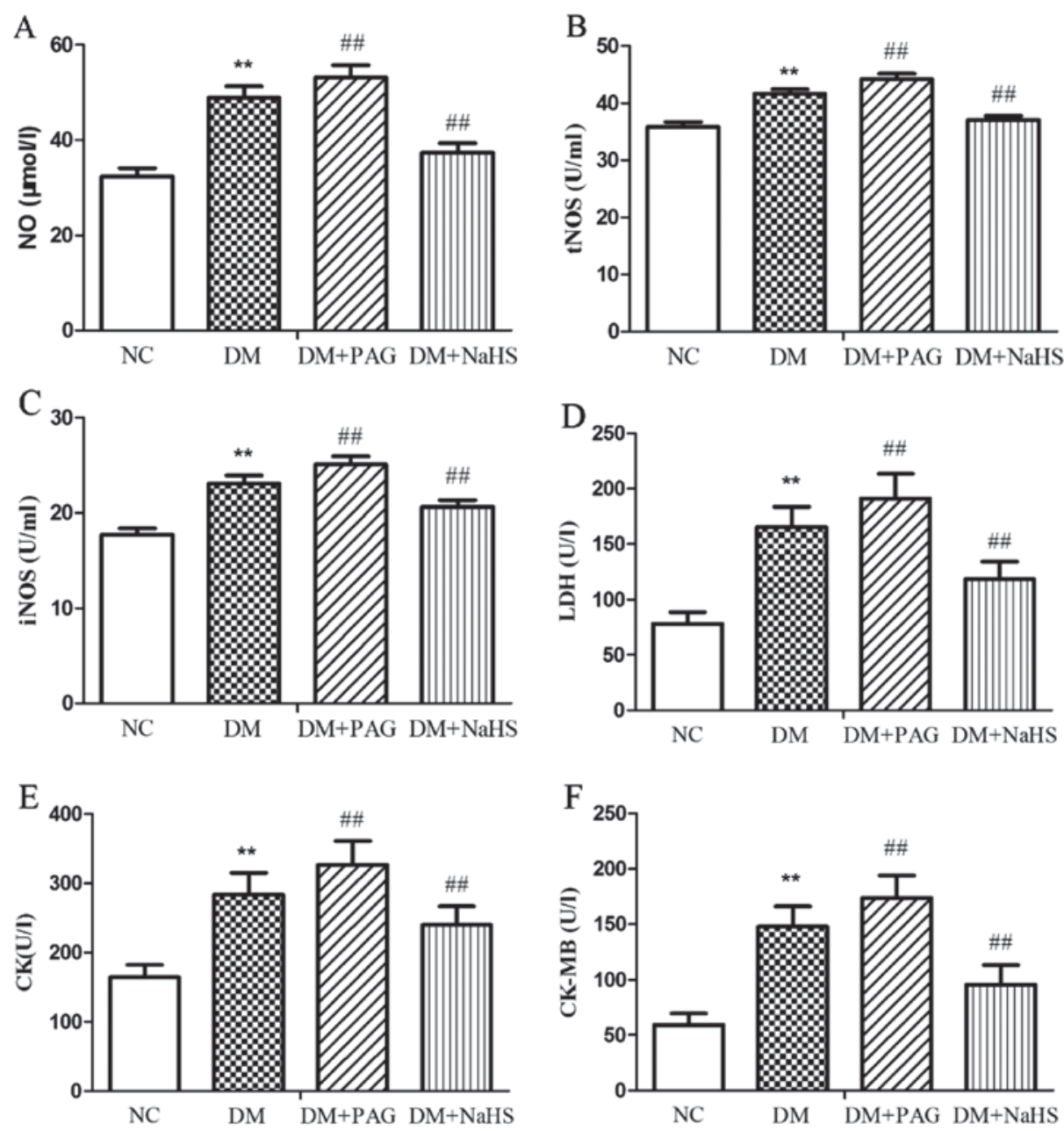

Figure 1. Effects of $\mathrm{H}_{2} \mathrm{~S}$ on (A) NO content, (B) tNOS activity, (C) iNOS activity, (D) LDH activity, (E) CK activity and (F) CK-MB activity in the serum in the different groups. Data were expressed as the mean $\pm \mathrm{SD}(n=8) .{ }^{* * *} \mathrm{P}<0.01 \mathrm{vs}$. NC group; ${ }^{* \#} \mathrm{P}<0.01$ vs. DM group; NC, normal control group; DM, diabetes mellitus group; DM+PAG, DM treatment with PAG group; DM+NaHS, DM treatment with NaHS group; NO, nitric oxide; tNOS, total nitric oxide synthase; iNOS, inducible nitric oxide synthase; LDH, lactate dehydrogenase; CK, creatine kinase; CK-MB, creatine kinase MB isozyme.

Changes of $N O$ content and tNOS, iNOS, $L D H, C K, C K-M B$ activities in serum. Compared with the $\mathrm{NC}$ group, $\mathrm{NO}$ content and tNOS, iNOS, LDH, CK, CK-MB activitives in the serum were all increased $(\mathrm{P}<0.01)$ in the DM group; in contrast to DM group, NO content and tNOS, iNOS, LDH, CK, CK-MB activitives in the serum were all increased $(\mathrm{P}<0.01)$ in the DM+PAG group; NO content and tNOS, iNOS, LDH, CK, CK-MB activitives were decreased $(\mathrm{P}<0.01)$ in the $\mathrm{DM}+\mathrm{NaHS}$ group (Fig. 1).

Changes of MDA content and SOD activity in myocardial tissue. Compared with the NC group, MDA content was increased $(\mathrm{P}<0.01)$ and SOD activity was decreased $(\mathrm{P}<0.01)$ in the DM group; in contrast to DM group, MDA content was increased $(\mathrm{P}<0.01)$ and SOD activity was decreased $(\mathrm{P}<0.01)$ in the $\mathrm{DM}+\mathrm{PAG}$ group; MDA content was decreased $(\mathrm{P}<0.01)$ and SOD activity was increased $(\mathrm{P}<0.01)$ in the $\mathrm{DM}+\mathrm{NaHS}$ group (Fig. 2).

Changes of NO content and tNOS, iNOS activities in myocardial tissue. Compared with the $\mathrm{NC}$ group, $\mathrm{NO}$ content and tNOS, iNOS activitives in the myocardial tissue were all increased $(\mathrm{P}<0.01)$ in $\mathrm{DM}$ group; in contrast to DM group, NO content and tNOS, iNOS activitives were all increased $(\mathrm{P}<0.05, \mathrm{P}<0.01)$ in the DM+PAG group; NO content and tNOS, iNOS activitives were decreased $(\mathrm{P}<0.01)$ in the DM+NaHS group (Fig. 3).

Histological changes in myocardial tissue. In the NC group, the myocardial fibers were arranged in neat rows, the myocardial nuclei were clear and the myocardial gap was normal. In the DM group however, the myocardial fibers were disordered, the myocardium was swollen and the myocardial gap was widened. Inflammatory cells had infiltrated and the cytoplasm was uneven in this group. Compared to the DM group, the myocardial damage in the DM+PAG group was more severe. The myocardial damage in the DM+NaHS group was relatively less and most of the cardiomyocytes were arranged neatly. Only a part of the myocardium was swollen, with the dissolution and rupture of a few myocardial fibers and the infiltration of some inflammatory cells (Fig. 4).

Changes in the myocardial ultrastructure. In the NC group, the sarcomeres of the myocardium were arranged in order and maintained homogenous length; the nuclei were normal and the mitochondria were arranged orderly between myofibrils. In the DM group, the integrity of the cardiomyocytes was 

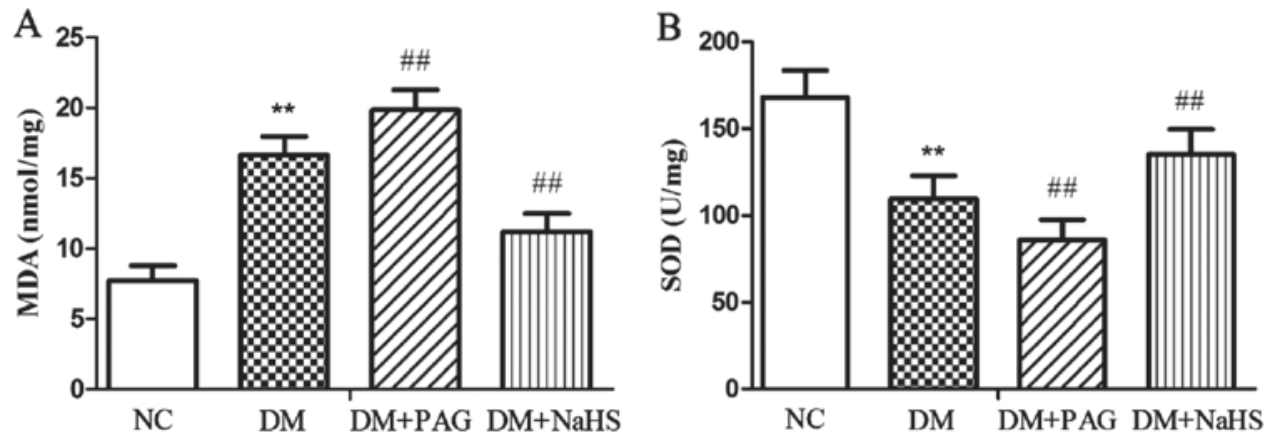

Figure 2. Effects of $\mathrm{H}_{2} \mathrm{~S}$ on (A) MDA content and (B) SOD activity in the myocardial tissue in the different groups. Data were expressed as the mean \pm SD $(n=8) .{ }^{* *} \mathrm{P}<0.01$ vs. NC group; ${ }^{\# \#} \mathrm{P}<0.01$ vs. DM group; NC, normal control group; DM, diabetes mellitus group; DM+PAG, DM treatment with PAG group; DM+NaHS, DM treatment with NaHS group; MDA, Malondialdehyde; SOD, superoxide dismutase.
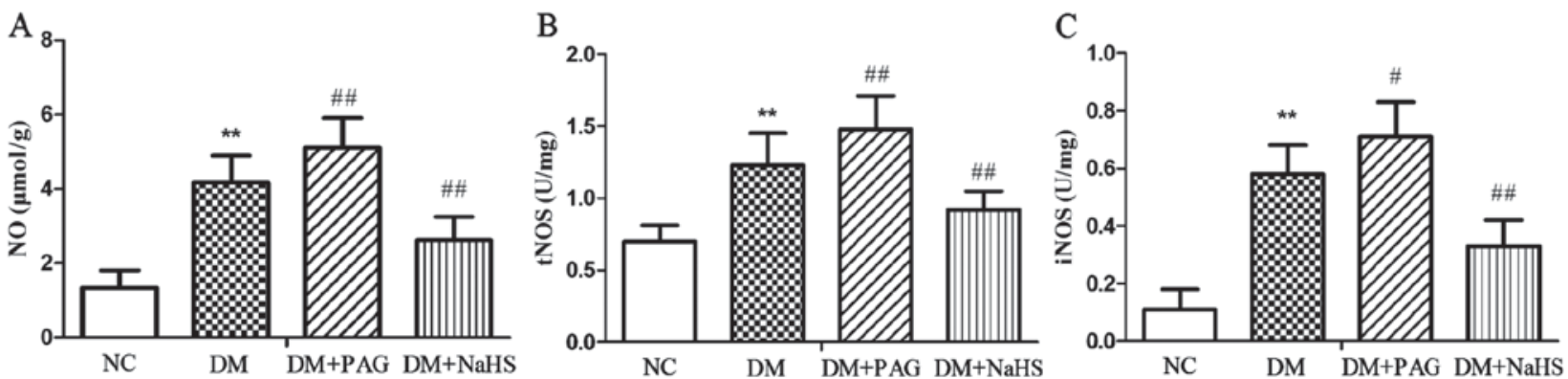

Figure 3. Effects of $\mathrm{H}_{2} \mathrm{~S}$ on (A) NO content, (B) tNOS activity and (C) iNOS activity in the myocardial tissue in the different groups. Data were expressed as the mean $\pm \mathrm{SD}(n=8)$. ${ }^{* *} \mathrm{P}<0.01$ vs. NC group; ${ }^{\#} \mathrm{P}<0.05$, ${ }^{\# \#} \mathrm{P}<0.01$ vs. DM group; $\mathrm{NC}$, normal control group; DM, diabetes mellitus group; DM+PAG, DM treatment with PAG group; DM+NaHS, DM treatment with NaHS group; NO, nitric oxide; tNOS, total nitric oxide synthase; iNOS, inducible nitric oxide synthase.

destroyed and mitochondrial matrix was severely damaged. In addition, the mitochondria were swollen and their cristae were vague. In the DM+PAG group, the severity of cardiomyocyte injury was aggravated compared with that in the DM group. Following treatment with NaHS, these injuries were ameliorated in the DM+NaHS group (Fig. 5).

Changes in myocardial iNOS at mRNA and protein level. Compared with the NC group, levels of myocardial iNOS mRNA and protein were significantly increased $(\mathrm{P}<0.01)$ in the DM group. Compared with the DM group, levels of myocardial iNOS mRNA and protein were increased $(\mathrm{P}<0.05$, $\mathrm{P}<0.01)$ in the DM+PAG group; levels of myocardial iNOS mRNA and protein were significantly decreased $(\mathrm{P}<0.01)$ in the DM+NaHS group (Figs. 6,7).

\section{Discussion}

DM, marked by an absolute or relative deficiency of insulin secretion, is a metabolic disorder syndrome characterized by hyperglycemia. DCM is a specific myocardial disease associated with DM and characterized by cardiac microvascular disease. Our data showed that compared with the NC group, the FBG level, HW/BW ratio, LVEDP, serum LDH, CK and CK-MB activities were increased, while LVSP and $\pm d p / d t_{\max }$ were decreased in the DM group. There were histological changes and ultrastructure damage in the DM group. These results demonstrated that sustained high blood glucose may damage the structure and function of cardiomyocytes.
$\mathrm{H}_{2} \mathrm{~S}$ is considered as the third endogenous signaling gasotransmitter which regulates cardiovascular function. Endogenous $\mathrm{H}_{2} \mathrm{~S}$ is produced bypyridoxal-5'-phosphate-dependent enzymes, including cystathionine- $\beta$-synthase (CBS) and CSE in mammalian tissues during cysteine metabolism $(14,15)$. CBS is the predominant $\mathrm{H}_{2} \mathrm{~S}$-generating enzyme in the brain and nervous system, while CSE is mainly expressed in the cardiovascular system $(16,17)$. PAG is an irreversible CSE inhibitor that can decrease endogenous $\mathrm{H}_{2} \mathrm{~S}$ content, while NaHS is a donor of exogenous $\mathrm{H}_{2} \mathrm{~S}$. Our data showed that the administration of NaHS ameliorated cardiac hypertrophy and myocardial injury in DCM, as evidenced by the reduction of the $\mathrm{HW} / \mathrm{BW}$ ratio and $\mathrm{LDH}, \mathrm{CK}$ and $\mathrm{CK}-\mathrm{MB}$ activities, improvement of hemodynamic parameters, and alleviation of myocardial histological changes and ultrastructure damage. In contrast, the rats in the DM+PAG group showed the opposite effect, which further verified that $\mathrm{H}_{2} \mathrm{~S}$ played a cardioprotective role in rats with DCM. Meanwhile, it raised the question as to the exact mechanism by which $\mathrm{H}_{2} \mathrm{~S}$ exerted its cardioprotective effect. To answer this, we analyzed the NO content and tNOS, and iNOS activities in the following experiments.

Both $\mathrm{NO}$ and $\mathrm{H}_{2} \mathrm{~S}$ are involved in the regulation of a wide range of physiological processes $(18,19)$. NO, the first short-lived gaseous lipophilic molecule, can be produced in almostall tissues. Severalstudies have reported theinvolvement of $\mathrm{NO}$ in myocardial contraction and in the regulation of cardiac function. Low concentrations of NO increase the myocardial contractility, while high concentrations of NO 

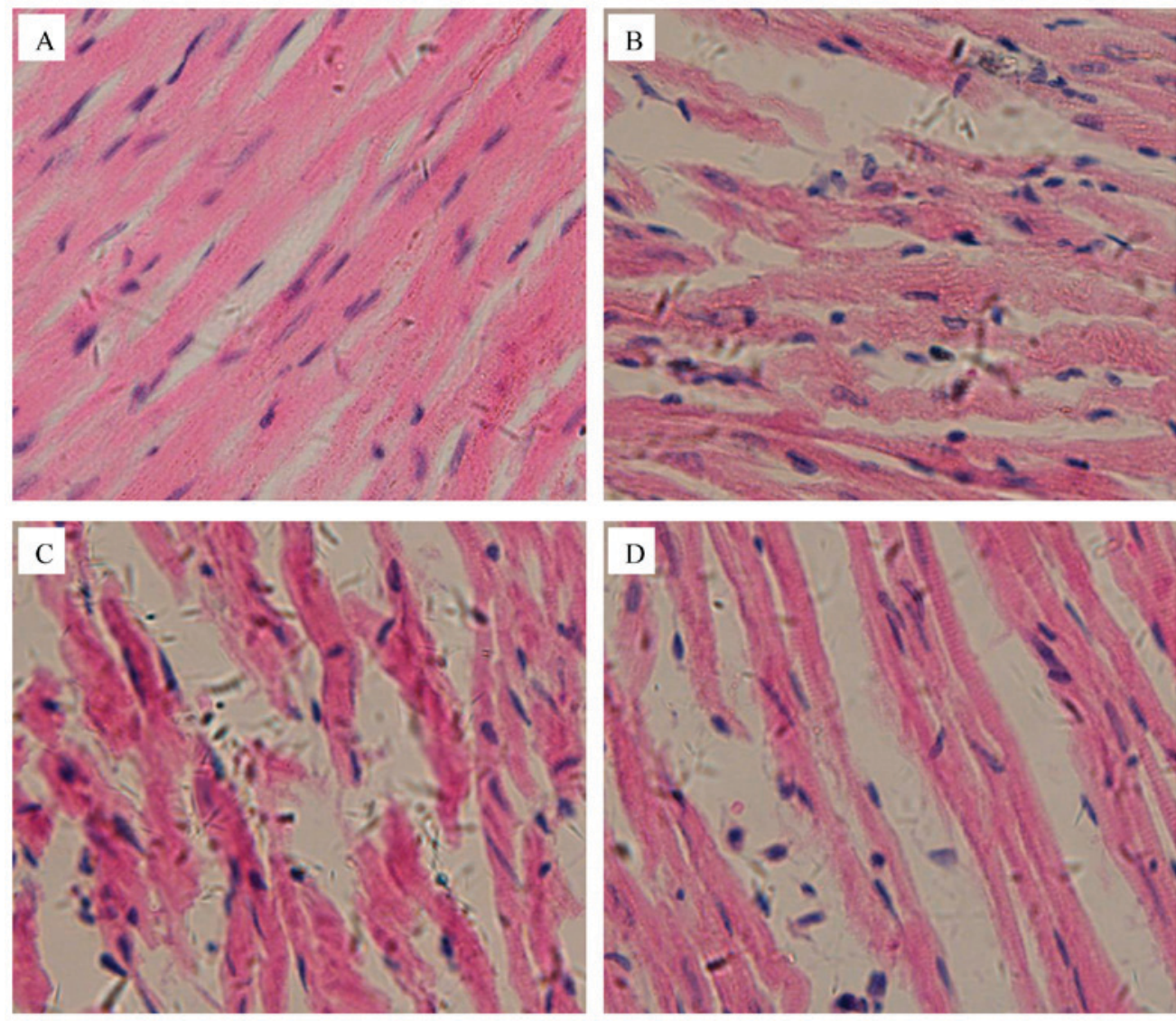

Figure 4. Histological changes of myocardial tissue in the different groups (x400). (A) NC group; (B) DM group; (C) DM+PAG group; (D) DM+NaHS group.
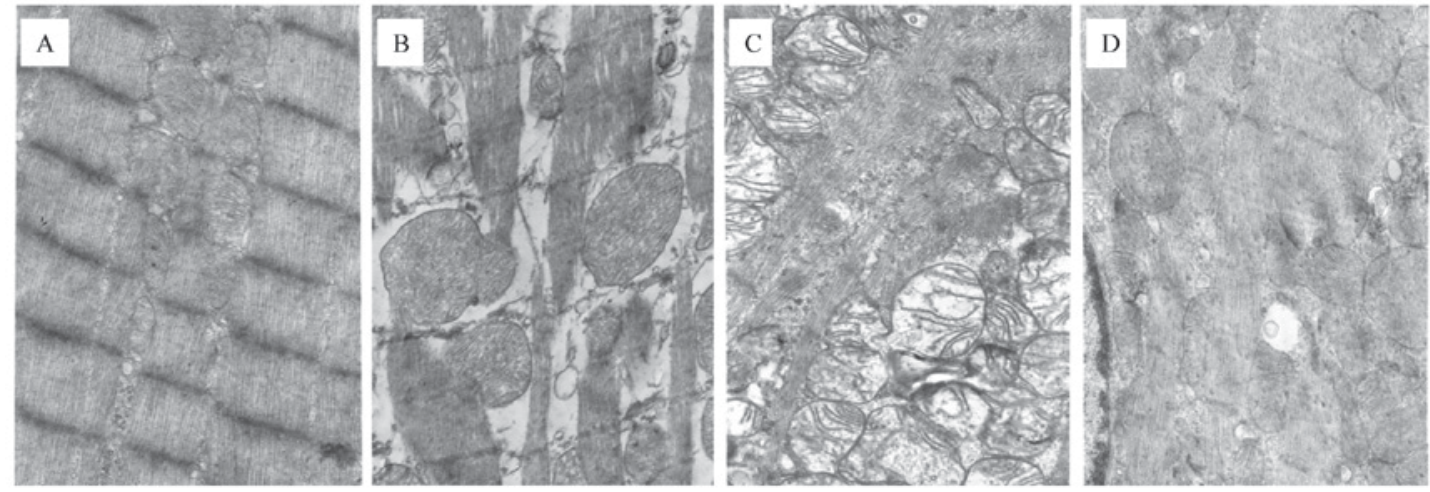

Figure 5. Changes of myocardium ultrastructure under transmission electron microscopy in the different groups (x15,000). (A) NC group; (B) DM group; (C) DM+PAG group; (D) DM+NaHS group.

can inhibit the myocardial contractility (8). In addition, high concentrations of $\mathrm{NO}$ can react with superoxide anions to produce cytotoxic peroxynitrite anions. This reaction accelerates the process of lipid peroxidation, and as the body produces excessive oxygen free radicals, oxidative stress injury, aggravated cell damage, and even death may result (20). Our results showed that the myocardial and serum NO contents were significantly increased in the DM group compared with the NC group. In vivo, oxygen free radicals can react with polyunsaturated fatty acids to produce lipid peroxides, and therefore the content of MDA can reflect the degree of myocardial oxidative stress injury. SOD is able to scavenge oxygen free radicals, convert it to oxygen and water, and thus is a detection index of the intracellular reduction power level (21). The experimental results wherein myocardial MDA content increased and SOD activity decreased in diabetic rats, indicated that there was oxidative stress injury in the diabetic myocardium. Therefore, we concluded that high concentrations of $\mathrm{NO}$ were harmful to the myocardium. Endogenous NO is constitutively or inductively synthesized in a reaction catalyzed by the NOS family in mammalian cells (22). The NOS family has three distinct NOS isoforms: neuronal (nNOS or NOS-1), inducible (iNOS or NOS-2) and endothelial (eNOS or NOS-3) NOS, which 

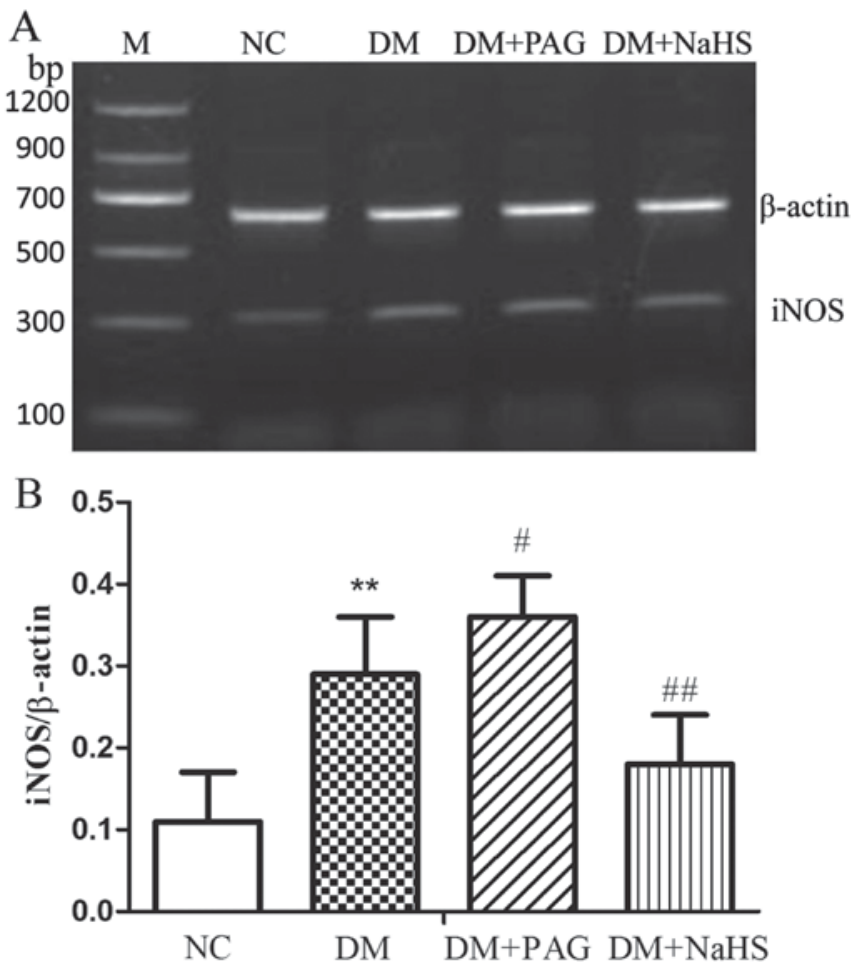

Figure 6. Expression levels of myocardial (A) iNOS mRNA and (B) quantification of the iNOS/ $\beta$-actin in the different groups. Data were expressed as the mean $\pm \mathrm{SD}(n=8) .{ }^{* *} \mathrm{P}<0.01$ vs. $\mathrm{NC}$ group; ${ }^{\# \mathrm{P}}<0.05,{ }^{\# \#} \mathrm{P}<0.01$ vs. $\mathrm{DM}$ group; NC, normal control group; DM, diabetes mellitus group; DM+PAG, DM treatment with PAG group; DM+NaHS, DM treatment with NaHS group; iNOS, inducible nitric oxide synthase.

are encoded by three different genes (23). eNOS and nNOS are known as constitutive NOS (cNOS) $(24,25)$, as under normal physiological conditions, cNOS exhibits constitutive expression and is involved in physiological signaling and in cellular maintenance. However, it is noteworthy that iNOS is localized throughout the cytoplasm in mammalian cells, and they can be induced to synthesize much more NO than cNOS (26). In certain pathological conditions such as cellular stress, hyperglycemia and ischemia-reperfusion, iNOS is often induced to produce higher NO $(27,28)$. We therefore detected tNOS and iNOS activities in the serum and myocardium, and the results showed that tNOS and iNOS activities were significantly higher in diabetic rats. The iNOS activities in the serum and in the myocardium were significantly different; however, the difference in cNOS activity was not obvious. Therefore, we deduced that the high concentration of NO in the myocardial tissue was induced mainly by iNOS. The significantly increased expression of iNOS mRNA and protein in diabetic rats compared to normal rats confirmed that iNOS overexpression led to the high concentrations of NO in the diabetic myocardium.

Several studies have discussed the interaction of $\mathrm{H}_{2} \mathrm{~S}$ with NO in various systems $(19,29)$. Studies have reported that exogenous $\mathrm{H}_{2} \mathrm{~S}$ could suppress iNOS activity and expression. In RAW 264.7 macrophages, a $\mathrm{H}_{2} \mathrm{~S}$ donor could inhibit iNOS protein expression and exerted an anti-inflammatory effect (30). In the metabolic syndrome model of rats, exogenous administration of NaHS could inhibit iNOS activity and reduce NO content in the plasma and myocardium to improve

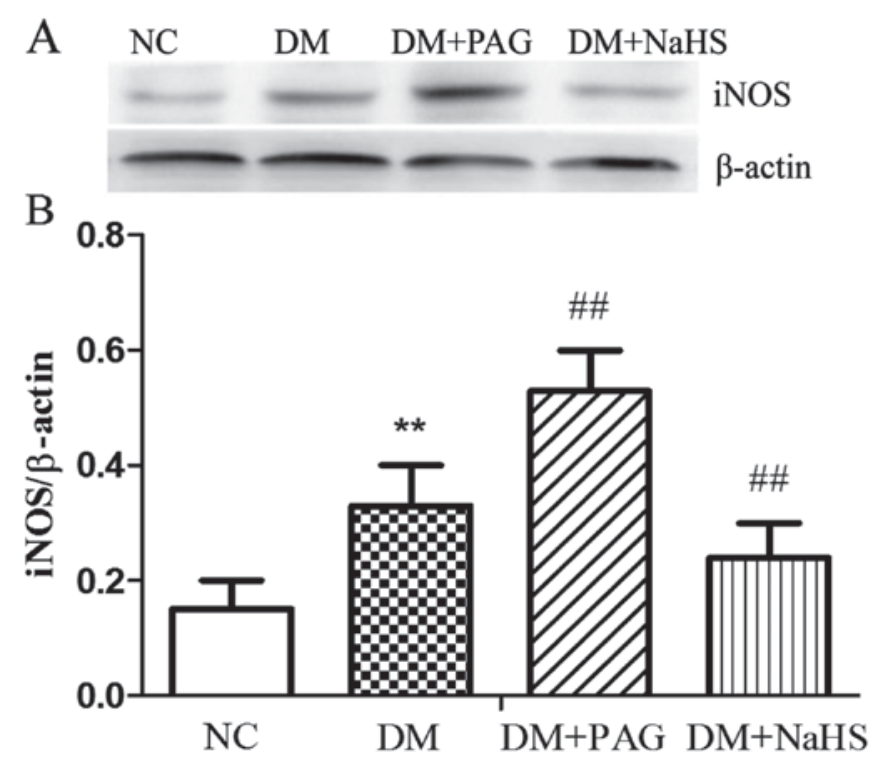

Figure 7. (A) Representative western blot and (B) quantitative analysis of the iNOS/ $\beta$-actin protein expression ratio in the myocardial tissue of different groups. Data were expressed as the mean $\pm \mathrm{SD}(n=8) .{ }^{* *} \mathrm{P}<0.01$ vs. NC group; ${ }^{\# \#} \mathrm{P}<0.01$ vs. DM group; NC, normal control group; DM, diabetes mellitus group; DM+PAG, DM treatment with PAG group; DM+NaHS, DM treatment with NaHS group; iNOS, inducible nitric oxide synthase.

cardiac function (31). Hua et al (32) found that exogenous $\mathrm{H}_{2} \mathrm{~S}$ could provide protection against Coxsackie virus B3-induced myocardial damage in mice through the suppression of myocardial iNOS mRNA and protein expression. Our data similarly showed that in the DM+NaHS group, iNOS activity and its mRNA and protein expression were significantly decreased, while its activity and expression were significantly increased in the DM+PAG group. Therefore, we inferred that iNOS expression in rats with DCM positively correlated with the severity of myocardial injury. This suggested that the overproduction of iNOS induced by $\mathrm{H}_{2} \mathrm{~S}$ inhibition exacerbated myocardial injury.

In addition, our data also showed that MDA and NO contents were decreased and SOD activity was increased in the DM+NaHS group, while the rats in the DM+PAG group showed the opposite effects. Therefore, without $\mathrm{H}_{2} \mathrm{~S}$ or with a lower $\mathrm{H}_{2} \mathrm{~S}$ concentration, myocardial iNOS would be over-expressed, $\mathrm{NO}$ would be over-produced, and oxidative stress and myocardial damage would be aggravated in diabetic rats.

In conclusion, $\mathrm{H}_{2} \mathrm{~S}$ exerted a cardioprotective effect in the rat model of DCM, and its mechanism might be associated with the suppression of iNOS activity and expression, a decreased NO content, a reduction in the formation of lipid peroxides, and thereby a suppression of the oxidative stress injury in order to protect the myocardial tissue.

\section{Acknowledgements}

The present study was supported by grants from the Natural Science Research Project of the Education Commission of Anhui Province (nos. KJ2015A163, KJ2017A216, KJ2017A210, KJ2015B006by) and the Natural Science Research Project of Bengbu Medical College (BYKY1621ZD). 


\section{References}

1. Rajesh M, Mukhopadhyay P, Bátkai S, Patel V, Saito K, Matsumoto S, Kashiwaya Y, Horváth B, Mukhopadhyay B, Becker L, et al: Cannabidiol attenuates cardiac dysfunction, oxidative stress, fibrosis, and inflammatory and cell death signaling pathways in diabetic cardiomyopathy. J Am Coll Cardiol 56: 2115-2125, 2010.

2. Gao Q, Wang XM, Ye HW, Yu Y, Kang PF, Wang HJ, Guan SD and $\mathrm{Li} \mathrm{ZH}$ : Changes in the expression of cardiac mitofusin-2 in different stages of diabetes in rats. Mol Med Rep 6: 811-814, 2012

3. Tarquini R, Lazzeri C, Pala L, Rotella CM and Gensini GF: The diabetic cardiomyopathy. Acta Diabetol 48: 173-181, 2011.

4. Zhang X and Chen C: A new insight of mechanisms, diagnosis and treatment of diabetic cardiomyopathy. Endocrine 41: 398-409, 2012.

5. Falcão-Pires I and Leite-Moreira AF: Diabetic cardiomyopathy: Understanding the molecular and cellular basis to progress in diagnosis and treatment. Heart Fail Rev 17: 325-344, 2012.

6. Wang R: Gasotransmitters: Growing pains and joys. Trends Biochem Sci 39: 227-232, 2014.

7. Vassilakopoulos T, Govindaraju K, Parthenis D, Eidelman DH, Watanabe Y and Hussain SN: Nitric oxide production in the ventilatory muscles in response to acute resistive loading. Am J Physiol Lung Cell Mol Physiol 292: L1013-L1022, 2007.

8. Rastaldo R, Pagliaro P, Cappello S, Penna C, Mancardi D, Westerhof $\mathrm{N}$ and Losano G: Nitric oxide and cardiac function. Life Sci 81: 779-793, 2007.

9. Łowicka E and Bełtowski J: Hydrogen sulfide (H2S)-the third gas of interest for pharmacologists. Pharmacol Rep 59: 4-24, 2007.

10. Liu YH, Lu M, Hu LF, Wong PT, Webb GD and Bian JS: Hydrogen sulfide in the mammalian cardiovascular system. Antioxid Redox Signal 17: 141-185, 2012.

11. Pan LL, Liu XH, Gong QH, Yang HB and Zhu YZ: Role of cystathionine $\gamma$-lyase/hydrogen sulfide pathway in cardiovascular disease: A novel therapeutic strategy? Antioxid Redox Signal 17: 106-118, 2012.

12. Yang R, Jia Q, Liu X, Wang Y, Gao Q and Ma S: Effect of hydrogen sulfide on cardiac myosin light chain kinase expression in diabetic rats. Zhong Nan Da Xue Xue Bao Yi Xue Ban 41 353-358, 2016 (In Chinese)

13. Kubo S, Kurokawa Y, Doe I, Masuko T, Sekiguchi F and Kawabata A: Hydrogen sulfide inhibits activity of three isoforms of recombinant nitric oxide synthase. Toxicology 241: 92-97, 2007.

14. Kabil O and Banerjee R: Redox biochemistry of hydrogen sulfide. J Biol Chem 285: 21903-21907, 2010.

15. Ji Y,Pang QF, Xu G, Wang L, Wang JK and Zeng YM: Exogenous hydrogen sulfide postconditioning protects isolated rat hearts against ischemia-reperfusion injury. Eur J Pharmacol 587: 1-7, 2008.

16. Whiteman M and Winyard PG: Hydrogen sulfide and inflammation: The good, the bad, the ugly and the promising. Expert Rev Clin Pharmacol 4: 13-32, 2011.
17. Wang R: Physiological implications of hydrogen sulfide: A whiff exploration that blossomed. Physiol Rev 92: 791-896, 2012.

18. Altaany Z, Moccia F, Munaron L, Mancardi D and Wang R: Hydrogen sulfide and endothelial dysfunction: Relationship with nitric oxide. Curr Med Chem 21: 3646-3661, 2014.

19. Lo Faro ML, Fox B, Whatmore JL, Winyard PG and Whiteman M: Hydrogen sulfide and nitric oxide interactions in inflammation. Nitric Oxide 41: 38-47, 2014.

20. Pacher P, Beckman JS and Liaudet L: Nitric oxide and peroxynitrite in health and disease. Physiol Rev 87: 315-424, 2007.

21. Yang R, Jia Q, Liu XF, Gao Q, Wang L and Ma SF: Effect of hydrogen sulfide on oxidative stress and endoplasmic reticulum stress in diabetic cardiomyopathy. Zhongguo Ying Yong Sheng Li Xue Za Zhi 32: 8-12, 2016 (In Chinese).

22. Khanna S, Singh GB and Khullar M: Nitric oxide synthases and diabetic cardiomyopathy. Nitric Oxide 43: 29-34, 2014.

23. Dellamea BS, Leitão CB, Friedman R and Canani LH: Nitric oxide system and diabetic nephropathy. Diabetol Metab Syndr 6: 17, 2014.

24. Barouch LA, Harrison RW, Skaf MW, Rosas GO, Cappola TP, Kobeissi ZA, Hobai IA, Lemmon CA, Burnett AL, O'Rourke B, et al: Nitric oxide regulates the heart by spatial confinement of nitric oxide synthase isoforms. Nature 416: 337-339, 2002.

25. Simon JN, Duglan D, Casadei B and Carnicer R: Nitric oxide synthase regulation of cardiac excitation-contraction coupling in health and disease. J Mol Cell Cardiol 73: 80-91, 2014.

26. Shah AM and MacCarthy PA: Paracrine and autocrine effects of nitric oxide on myocardial function. Pharmacol Ther 86: 49-86, 2000.

27. Gealekman O, Abassi Z, Rubinstein I, Winaver J and Binah O: Role of myocardial inducible nitric oxide synthase in contractile dysfunction and beta-adrenergic hyporesponsiveness in rats with experimental volume-overload heart failure. Circulation 105: 236-243, 2002.

28. Soliman H, Craig GP, Nagareddy P, Yuen VG, Lin G, Kumar U, McNeill JH and Macleod KM: Role of inducible nitric oxide synthase in induction of RhoA expression in hearts from diabetic rats. Cardiovasc Res 79: 322-330, 2008.

29. Nagpure BV and Bian JS: Interaction of hydrogen sulfide with nitric oxide in the cardiovascular system. Oxid Med Cell Longev 2016: 6904327, 2016.

30. Li L, Salto-Tellez M, Tan CH, Whiteman M and Moore PK: GYY4137, a novel hydrogen sulfide-releasing molecule, protects against endotoxic shock in the rat. Free Radic Biol Med 47: 103-113, 2009.

31. Rong-na L, Xiang-jun Z, Yu-han C, Ling-qiao L and Gang H: Interaction between hydrogen sulfide and nitric oxide on cardiac protection in rats with metabolic syndrome. Zhongguo Yi Xue Ke Xue Yuan Xue Bao 33: 25-32, 2011 (In Chinese)

32. Hua W, Chen Q, Gong F, Xie C, Zhou S and Gao L: Cardioprotection of $\mathrm{H} 2 \mathrm{~S}$ by downregulating iNOS and upregulating HO-1 expression in mice with CVB3-induced myocarditis. Life Sci 93: 949-954, 2013. 